\title{
Usefulness of urinary NGAL levels during an operation in a patient with septic shock and acute kidney injury for determining postoperative initiation of renal replacement therapy: a case study
}

\author{
Eiko Wada ${ }^{1,2^{*}}$, Kohei Suganuma', Shigehiro Shibata ${ }^{1}$ and Kosei Otaka ${ }^{1}$
}

Keywords: Urinary neutrophil gelatinase-associated lipocalin (uNGAL), Acute kidney injury (AKI), Septic shock, Continuous hemodiafiltration (CHDF)

\section{To the editor}

Although urinary neutrophil gelatinase-associated lipocalin (uNGAL) is useful as a prognostic tool for initiating renal replacement therapy (RRT) [1], determining the timing of initiating RRT for septic shock with acute kidney injury (AKI) may be difficult. Therefore, we attempted to measure uNGAL levels during an operation to determine and prepare the initiation of postoperative RRT. We experienced a case of high uNGAL levels during an operation on a 78-year-old man who underwent emergency loop colostomy due to acute diffuse peritonitis. After open biopsy for a small intestinal tumor (Fig. 1a) on day 1, oliguria and reduced systolic blood pressure were observed on day 2 . Gastrointestinal perforation was suspected because contrast-enhanced computed tomography revealed free air (Fig. 1b). Levels of uNGAL at the beginning and at the end of the operation were 2461 and > $6000 \mathrm{ng} / \mathrm{mL}$, respectively (Fig. 2). Reductions in lactate and creatinine (Cre) levels, oliguria, and reduced systolic blood pressure were observed again on day 3 . Continuous hemodiafiltration (CHDF) was initiated

\footnotetext{
* Correspondence: eco.1121.w@gmail.com

${ }^{1}$ Department of Anesthesia, Omagari Kosei Medical Center, 8-65 Torimachi, Daisen 014-0027, Japan

${ }^{2}$ Department of Anesthesia and Intensive Care Medicine, Akita University Graduate School of Medicine, Akita, Japan
}

based on uNGAL levels with failure in RIFLE classification, and the patient's vital signs improved within the normal range.

Despite successful recovery using CHDF for septic shock with AKI, postoperative CHDF was deferred until the morning of the following day due to reduced Cre and lactate levels. In current clinical practice, AKI is diagnosed by measuring Cre and/or blood urea nitrogen levels, but these markers are insensitive and late indicators of AKI [2]. Previous studies demonstrated that uNGAL levels for AKI were increased within $2 \mathrm{~h}$, and a diagnosis using Cre levels was delayed by 1 to 3 days [3, 4], which may be consistent with our case. Alternatively, perioperative management, such as oxygenation by anesthesia and/or improvement of the circulation during the operation by sufficient fluid administration, potentially caused difficulties in increased lactate or Cre levels after the operation. Further studies are necessary to determine this issue.

uNGAL may be a useful indicator for septic AKI because it is increased by not only AKI but also by inflammation $[5,6]$. Although the cutoff value of uNGAL levels for predicting AKI is $193.2 \mathrm{ng} / \mathrm{mL}$ $($ AUC $=0.837)$ [3], the median value of uNGAL in patients with septic shock without AKI is $471 \mathrm{ng} / \mathrm{mL}$ 

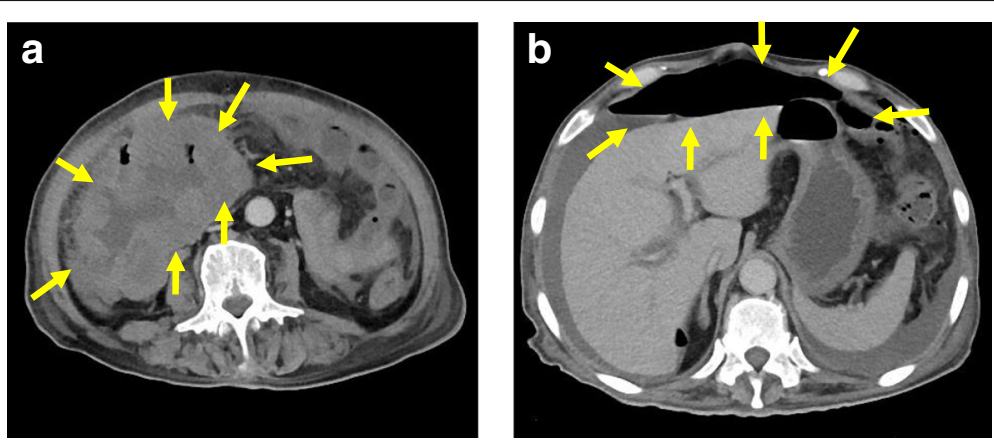

Fig. 1 a Image of a small intestinal tumor in our patient. The arrows indicate a small intestinal tumor. $\mathbf{b}$ Image of contrast-enhanced computed tomography $(C T)$ in our patient. The arrows indicate free air

[7]. Therefore, differentiating between AKI and septic shock without AKI by measuring only uNGAL levels is difficult. However, once the septic shock is complicated by AKI, the median value of uNGAL increases to $803 \mathrm{ng} / \mathrm{mL}$ [7]. CHDF may also be useful for a septic shock as well as AKI [8]. We used polymethylmethacrylate(PMMA) as a membrane of CHDF, and this membrane continuously and efficiently removes various cytokines from the blood [9]. Therefore, CHDF might, at least in part, have led to the recovery of our patient from AKI and septic shock.

Early evaluation of uNGAL levels during an operation may be useful information for prompt determination and preparation of postoperative initiation of RRT in patients with septic shock accompanied by AKI when lactate or Cre levels might be undetectable after perioperative management.

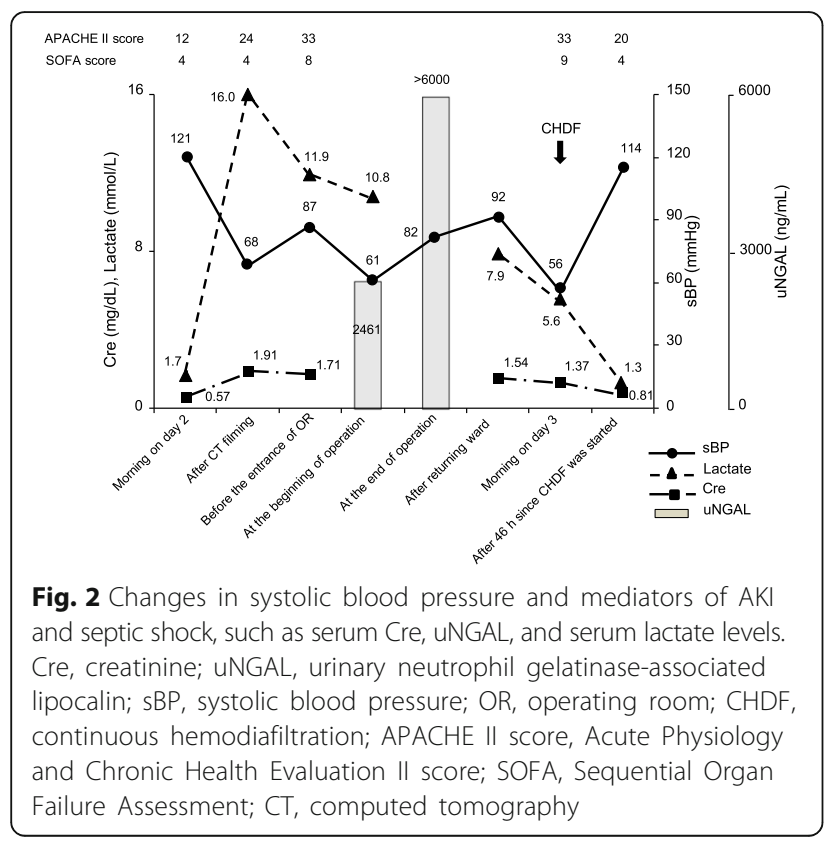

\section{Abbreviations}

AKI: Acute kidney injury; CHDF: Continuous hemodiafiltration; Cre: Creatinine; PMMA: Polymethylmethacrylate; SBP: Systolic blood pressure; UNGAL: Urinary neutrophil gelatinase-associated lipocalin

\section{Acknowledgements}

We thank Dr. Satoshi Sunaga and Dr. Ayaka Sakyo for reading the manuscript and Springer Nature Author Services for editing a draft of this manuscript.

\section{Authors' contributions}

$\mathrm{KO}$ and SS contributed to the study conception and collected the data. EW and SS analyzed the data and drafted the manuscripts. EW and KS revised the manuscripts. All authors read and approved the final manuscript.

\section{Consent for publication}

Written informed consent was obtained from the patient and family for publication of the case report and accompanying images.

\section{Competing interests}

The authors declare that they have no competing interests.

\section{Publisher's Note}

Springer Nature remains neutral with regard to jurisdictional claims in published maps and institutional affiliations.

Received: 7 February 2018 Accepted: 10 April 2018

Published online: 19 April 2018

\section{References}

1. Fan $\mathrm{H}$, Zhao $\mathrm{Y}$, Zhu JH, Song FC. Urine neutrophil gelatinase-associated lipocalin in septic patients with and without acute kidney injury. Ren Fail. 2014;36:1399-403.

2. Abraham BP, Frazier EA, Morrow WR, Blaszak RT, Devarajan P, Mitsnefes M, Bryant JC, Sachdeva R. Cystatin C and neutrophil gelatinase-associated lipocalin as markers of renal function in pediatric heart transplant recipients. Pediatr Transplant. 2011;15:564-9.

3. Mishra J, Dent C, Tarabishi R, Mitsnefes MM, Ma Q, Kelly C, Ruff SM, Zahedi K, Shao M, Bean J, Mori K, Barasch J, Devarajan P. Neutrophil gelatinaseassociated lipocalin (NGAL) as a biomarker for acute renal injury after cardiac surgery. Lancet. 2005;365:1231-8.

4. Bennett M, Dent CL, Ma Q, Dastrala S, Grenier F, Workman R, Syed H, Ali S, Barasch J, Devarajan P. Urine NGAL predicts severity of acute kidney injury after cardiac surgery: a prospective study. Clin J Am Soc Nephrol. 2008:3:665-73.

5. Bellomo R, Ronco C, Kellum JA, Mehta RL, Palevsky P, Acute Dialysis Quality Initiative workgroup. Acute renal failure-definition, outcome measures, animal models, fluid therapy and information technology needs: the Second International Consensus Conference of the Acute Dialysis Quality Initiative (ADQI) Group. Crit Care. 2004;8:R204-12. 
6. Kjeldsen $L$, Johnsen AH, Sengeløv $H$, Borregaard N. Isolation and primary structure of NGAL, a novel protein associated with human neutrophil gelatinase. J Biol Chem. 1993;268:10425-32.

7. Kim H, Hur M, Lee S, Marino R, Magrini L, Cardelli P, Struck J, Bergmann A, Hartmann O, Di Somma S, GREAT Network. Proenkephalin, neutrophil gelatinase-associated lipocalin, and estimated glomerular filtration rates in patients with sepsis. Ann Lab Med. 2017;37:388-97.

8. Oda S, Aibiki M, Ikeda T, Imaizumi H, Endo S, Ochiai R, Kotani J, Shime N, Nishida O, Noguchi T, Matsuda N, Hirasawa H. Sepsis Registry Committee of the Japanese Society of Intensive Care Medicine. The Japanese guidelines for the management of sepsis. J Intensive Care. 2014;2:55.

9. Nakada TA, Oda S, Matsuda K, Sadahiro T, Nakamura M, Abe R, Hirasawa H. Continuous hemodiafiltration with PMMA hemofilter in the treatment of patients with septic shock. Mol Med. 2008;14:257-63.

\section{Submit your manuscript to a SpringerOpen ${ }^{\circ}$ journal and benefit from:}

- Convenient online submission

- Rigorous peer review

- Open access: articles freely available online

- High visibility within the field

- Retaining the copyright to your article

Submit your next manuscript at $\boldsymbol{\sim}$ springeropen.com 